\title{
Transforming Growth Factor Beta-Induced Connective Tissue Growth Factor and Chronic Allograft Rejection ${ }^{\dagger}$
}

\author{
K. Csencsits ${ }^{a} \ddagger$, S. C. Wood ${ }^{a} \ddagger$, G. Lu ${ }^{a}$, \\ S. M. Faust ${ }^{b}$, D. Brigstock ${ }^{e}$, E. J. Eichwald ${ }^{d}$, \\ C. G. Orosz ${ }^{f}$ and D. K. Bishop ${ }^{\mathrm{a}, c, *}$ \\ a From the Section of General Surgery, Department of \\ Surgery and ${ }^{\mathrm{b}}$ Departments of Human Genetics and \\ ${ }^{c}$ Microbiology and Immunology, University of Michigan \\ School of Medicine, Ann Arbor, MI 48109; \\ ${ }^{\mathrm{d}}$ Department of Pathology, University of Utah School of \\ Medicine, Salt Lake City, UT 84132; ${ }^{\mathrm{e}}$ Center for Cell and \\ Vascular Biology, Children's Research Institute and \\ ${ }^{\dagger}$ Division of Transplantation, Department of Surgery, Ohio \\ State University, Columbus, OH 43210 \\ *Corresponding author: D. K. Bishop, kbishop@umich.edu
}

Late loss of allograft function is primarily attributed to chronic rejection (CR). There are no effective treatments for CR and the underlying cause of the disease is unknown. This study compared events that occurred within cardiac allografts placed in mice that received either anti-CD4 therapy and develop CR or anti-CD40L therapy and do not develop CR. Both TGF $\beta$ and connective tissue growth factor (CTGF), which is induced by TGF , were expressed in grafts with CR but were not expressed in grafts without CR. TGF $\beta$ transfection of allografts in anti-CD40L-treated recipients resulted in CTGF expression and CR. However, TGF $\beta$ transfection of syngeneic grafts did not result in CTGF expression or CR. These data indicate that TGF $\beta$ alone is insufficient to induce CR and that CTGF is required. Further, antigenic stimulation is required for TGF $\beta$ induction of CTGF. Thus, CTGF may serve as a therapeutic target for CR.

Key words: Chronic rejection, connective tissue growth factor, fibrosis, transforming growth factor beta

Received 2 September 2005, revised 30 November 2005 and accepted for publication 16 December 2005

\section{Introduction}

Chronic rejection (CR) is the leading cause of late allograft loss, and is prevalent in cardiac, lung, renal and to

\footnotetext{
†This manuscript is dedicated to Dr. Charley Orosz, who passed away on August 7, 2005.

$¥ \mathrm{KC}$ and SCW contributed equally to this study.
}

a lesser degree, liver transplantation (reviewed in 1). CR is a progressive, irreversible disease that is characterized by deteriorating graft function, interstitial fibrosis and the occlusion of lumenal structures such as arteries and epithelial-lined conduits (reviewed in 2-4). In cardiac and renal allografts, subendothelial tissue develops in arteries forming an occlusive neointima, which is referred to as transplant-associated vasculopathy (TAV). Hence, TAV and interstitial fibrosis are commonly viewed as surrogate markers for $\mathrm{CR}$. These pathologic changes of $\mathrm{CR}$ are distinct from those observed during acute rejection, where inflammatory cell infiltration is associated with parenchymal cell death. Rather, these changes resemble chronic tissue remodeling and/or wound repair processes that follow tissue injury (3). Despite intense investigation, the etiology of CR and associated pathologies are very poorly understood. While both alloantigen-dependent (i.e. MHC disparity, No. of acute rejection episodes) and -independent (i.e. ischemia/reperfusion injury) factors contribute to the disease process (reviewed in 5,6), reliable therapeutic targets for prevention and treatment of $\mathrm{CR}$ have not been identified. As summed up by Tilney and colleagues (5), 'No tests can predict the development of the process and no drugs can control or reverse it'.

TGF $\beta$ has been implicated in a number of fibrotic diseases (7-10) including CR (11). TGF $\beta$ also has numerous immunosuppressive activities that are viewed as beneficial in the settings of inflammation and transplantation (reviewed in 12). Further, TGF $\beta$ acts as a tumor suppressor for several cell types, and interference with TGF $\beta$ receptor signaling may lead to cancer of epithelial cell origin (13). Hence, longterm inhibition of TGF $\beta$ as a treatment for CR could have detrimental consequences.

CTGF is an immediate early response gene product that is induced by TGF $\beta$ (reviewed in 14,15). TGF $\beta$, but not PDGF, FGF or EGF, has been shown to induce CTGF production from a variety of cell types, utilizing a unique TGF $\beta$ response element that is not associated with other TGF $\beta$ regulated promoters (16). CTGF mediates many of the fibrogenic activities of TGF $\beta$, but not its antimitogenic activity on epithelial cells $(8,14,17)$. CTGF is mitogenic for fibroblasts and induces the production of collagen and other extracellular matrix proteins from fibroblasts and mesangial cells. While CTGF has been implicated in a variety of fibrotic diseases (18-27), CTGF has received little attention in the setting of transplantation. Hence, the current study 
investigated the relationship between TGF $\beta$-induced CTGF and CR. Our observations suggest that CTGF may provide a target for preventing $C R$ while sparing the antiinflammatory and anti-proliferative activities of TGF $\beta$.

\section{Materials and Methods}

\section{Mice}

Female C57BL/6 $\left(\mathrm{H}-2^{\mathrm{b}}\right)$ mice and $\mathrm{BALB} / \mathrm{c}\left(\mathrm{H}-2^{\mathrm{d}}\right)$ mice were purchased from The Jackson Laboratories (Bar Harbor, ME) and housed under specific pathogen-free conditions in the Unit for Laboratory Animal Medicine at the University of Michigan. Mice were used between 6-12 weeks of age.

\section{Heterotopic cardiac transplantation}

C57BL/6 mice were transplanted with intact BALB/c cardiac allografts, as described (28). In this model, the donor heart is anastomosed to the great vessels of the abdomen, perfused with recipient mouse's blood and resumes contraction. Transplant function was monitored by abdominal palpation.

\section{Assessment of chronic rejection}

Functioning allografts were recovered at the indicated times posttransplantation, fixed in formalin and embedded in paraffin. Sections were stained with $\mathrm{H} \& \mathrm{E}$ to assess myocyte viability (i.e. presence of nuclei and cross striation). As described (29), trichrome and elastin stains were used to identify collagen deposition and the presence of neointima, respectively.

\section{Anti-CD4 and anti-CD40L therapies to prolong allograft survival} Anti-CD4 (hybridoma GK1.5, obtained from American Type Culture Collection, Manassas, VA) and anti-CD40L (hybridoma MR1, kindly provided by Dr. Randy Noelle, Dartmouth) mAb were purified and resuspended in PBS by Ligocyte Pharmaceuticals (Bozeman, MT). To transiently deplete CD4+ cells, allograft recipients were injected i.p. with $1 \mathrm{mg}$ of anti-CD4 mAb on days $-1,0$ and 7 relative to transplantation (29-31). CD4+ cells begin to repopulate the periphery between 3 and 4 weeks post-transplant. For inductive anti-CD4OL therapy, allograft recipients were injected i.p. with $1 \mathrm{mg}$ of anti-CD40L on days 0,1 and 2 relative to transplantation $(31,32)$.

\section{Adenoviral-mediated transfection of cardiac allografts}

As described $(33,34)$, cardiac allografts were transfected by perfusion via the aorta with $\mathrm{E} 1 / \mathrm{E} 3$ deleted adenoviral vectors $\left(5 \times 10^{8} \mathrm{pfu}\right)$ encoding the active form of human TGF $\beta 1$ (Ad-TGF $\beta$ ) or beta-galactosidase (Ad- $\beta$ gal). Following perfusion, donor grafts were recovered and placed in iced Ringer's for approximately $1 \mathrm{~h}$ prior to transplantation. Reporter gene studies with Ad- $\beta$ gal have revealed that the distribution of transgene expression within the cardiac graft is patchy, and that both cardiac myocytes and cells of the vasculature express the transgene product (33).

\section{RNA isolation and RT-PCR}

Cardiac allografts were homogenized in $1 \mathrm{ml}$ TRIzol囚 (Invitrogen Life Technologies, Carlsbad, CA) and RNA was isolated as per manufacturer's proto$\mathrm{col}$. Two $\mu \mathrm{g}$ of total RNA were reverse transcribed using a cDNA Cycle® Kit (Invitrogen Life Technologies) using oligo dT primers and AMV reverse transcriptase to generate cDNA. Human TGF $\beta 1$ (hTGF $\beta$ ) primers are specific for hTGF $\beta$ and do not amplify mouse TGF $\beta$ (mTGF $\beta$ ) (34). Primer sequences: hTGF $\beta$ sense 5' GTGGAAACCCACAACGAA 3', anti-sense 5' GGCGGCCGGTAGTGAAC 3'; mTGF $\beta$ sense 5' TGGCTTCTAGTGCTGACG 3', anti-sense 5' GTTGCTCCACACTTGAT 3'; CTGF sense 5' ATCCCTGCGACCCACACAAG 3', anti-sense $5^{\prime}$ CAACTGCTTTGGAAGGACTCGC $3^{\prime} ; \gamma$ actin sense $5^{\prime}$ CCACACAGAGTACTTGCGCTCAGG 3', anti-sense 5' CACCCTGTGCTGCTCACCGAGGCC 3'. Samples were amplified using AmpliTaq DNA polymerase (Perkin Elmer, Norwalk, CT) in a GeneAmp® PCR System 9700 (Applied Biosystems Inc, Foster City, CA).

\section{Quantitative RT-PCR}

CTGF primers are listed above. Collagen (pro-collagen 1a) sense $5^{\prime}$ TCCCTACTCAGCCGTCTGTGCC 3', anti-sense $5^{\prime}$ AGCCCTCGCTTCCGTACTCG 3'; GAPDH sense 5' CTGGTGCTGAGTATGTCGTG 3', anti-sense 5'
A
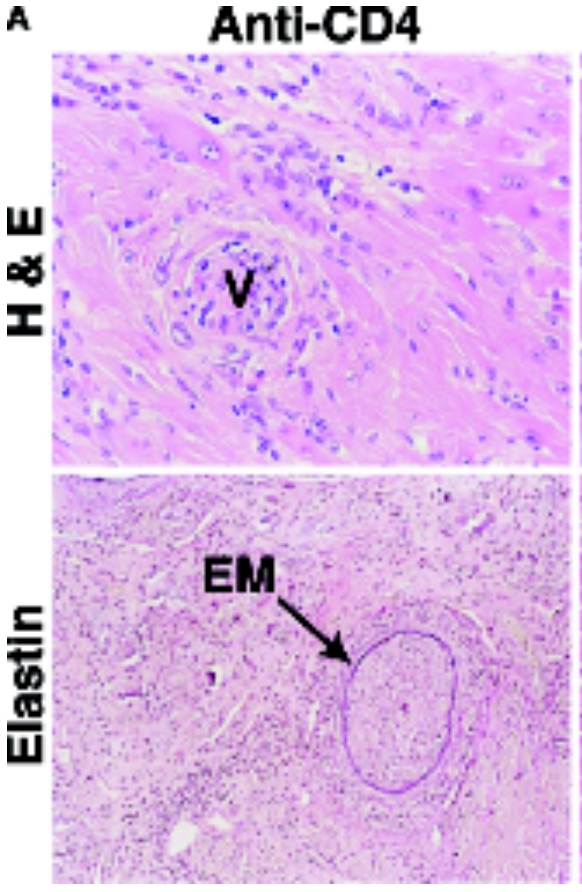

Anti-CD40L

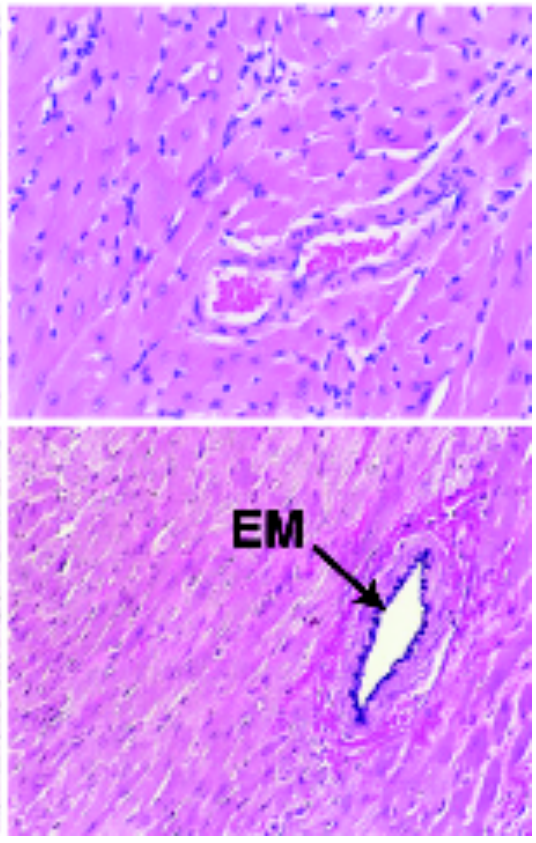

Figure 1. TGF $\beta$ and CTGF expression segregate with CR. C57BL/6 mice were transplanted with BALB/c cardiac allografts and were given inductive antiCD4 or anti-CD40L therapy. Functioning allografts were recovered on day 60 post-transplant. Panel A represents a histologic assessment of CR. $V=$ occluded vessel, EM = elastic membrane. Panel $\mathbf{B}$ depicts RT-PCR on RNA samples from 4 individual transplants per group. For mTGF $\beta$, data are representative of 10 of 10 transplants for the antiCD4 group and 15 of 17 (2 were weakly positive) for the anti-CD40L group. For CTGF, data are representative of 14 of 17 (3 were negative) transplants for the anti-CD4 group and 17 of 20 ( 3 were weakly positive) for the antiCD40L group. 

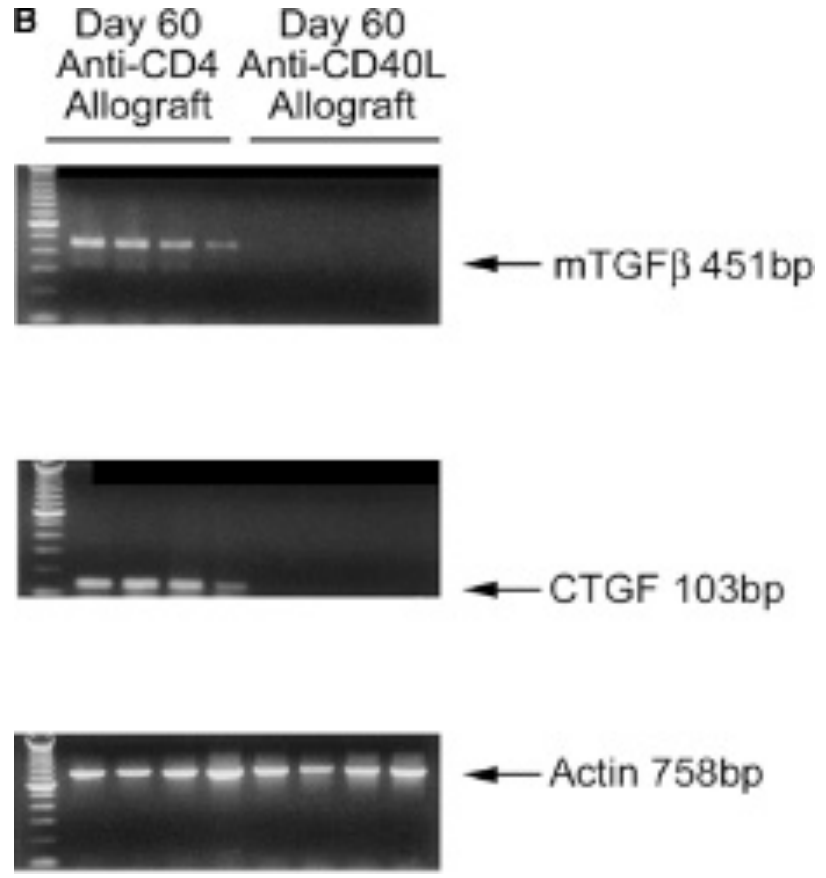

Figure 1. Continued.

CAGTCTTCTGAGTGGCAGTG 3'. Real-time PCR was performed on cDNA using a Cepheid Smart Cycler $\left.{ }^{(}\right)$System (Cepheid, Sunnyvale, CA) and primer binding to DNA was detected by SYBER Green ITM dye (Roche, Indianapolis, IN). Relative expression of CTGF and collagen is expressed as the exponent of the base 2 of the difference between the cycle threshold of CTGF or collagen versus GAPDH in transplant CDNA samples. Significance was determined with an unpaired t-test with Welch's correction.

\section{Immunohistochemistry for CTGF}

Allografts were paraffin embedded, sectioned, de-paraffinized and processed for antigen retrieval in citrate buffer (Biocare Medical, Concord, CA). Endogenous peroxidase was blocked using $0.3 \% \mathrm{H}_{2} \mathrm{O}_{2} / 0.1 \% \mathrm{NaN}_{3}$ in $\mathrm{dPBS}$ for 10 min prior to standard immunohistochemistry using affinitypurified rabbit anti-CTGF (35). Biotinylated goat anti-rabbit secondary Ab (1:150, BioSource International, Camarillo, CA) was added for 30 min, followed by incubation with a 1:500 dilution of SA-HRP (BioSource) in PBS for $30 \mathrm{~min}$. Sections were developed with AEC (Moss, Pasadena, CA) and counterstained with Harris hematoxylin (Fischer Scientific, Hampton, $\mathrm{NH}$.

\section{Results and Discussion}

\section{Development of CR following inductive anti-CD4 vs. anti-CD40L therapy}

We have previously reported that inductive therapy with either anti-CD4 $(30,31)$ or anti-CD40L $(31,32)$ mAb markedly prolongs cardiac allograft survival. However, at 60 days post-transplant functioning allografts in anti-CD4-treated recipients develop TAV and exhibit interstitial collagen deposition (29), while allografts in anti-CD40L-treated recipients do not (32) (Figure 1A).
Expression of TGF $\beta$ and CTGF is associated with $C R$ Since TGF $\beta$ has been associated with CR (reviewed in 11), we assessed intragraft expression of TGF $\beta$ on day 60 posttransplant (Figure 1B). TGF $\beta$ mRNA was readily detectable in the allografts of anti-CD4-treated mice but was absent in the anti-CD40L- treated group. This pattern of TGF $\beta$ expression was observed in at least 10 individual transplants per group. Since CTGF is induced by TGF $\beta$ (16) and is reported to mediate the fibrotic activity of $\operatorname{TGF} \beta(8,14)$, we assessed CTGF expression in long-term allografts (Figure 1B). CTGF expression paralleled that of TGF $\beta$ in at least 10 individual transplants per group. Thus, expression of TGF $\beta$ and CTGF segregated with the development of CR.

\section{Allograft transfection with TGF $\beta$ results in CTGF expression and CR in anti-CD40L-treated recipients} To further explore the relationship between TGF $\beta$-induced CTGF and CR, we transfected allografts with the active form of hTGF $\beta 1$ or $\beta$ gal and transplanted them into recipients that were treated with anti-CD40L mAb. Forced expression of active hTGF $\beta$, but not $\beta$ gal, induced intragraft expression of CTGF (Figure 2A) and resulted in the development of $\mathrm{CR}$ (Figure 2B) in anti-CD40L-treated recipients. This pattern of hTGF $\beta$ and CTGF expression, and CR was observed in at least 20 transplants per group.

Since TGF $\beta$ induces CTGF in a variety of cell types (16), we employed immunohistochemistry to localize CTGF in hTGF $\beta$-transfected allografts (Figure 2C). CTGF protein was readily identified in vascular endothelial cells and cellsinfiltrating vessels with TAV in hTGF $\beta$-transfected allografts, but not in uninvolved vessels in $\beta$ gal-transfected grafts.

The studies above were performed between days 50 and 60 post-transplantation. We have also assessed TGF $\beta$-induced CTGF expression at earlier time points following transplantation of Ad-TGF $\beta$-transfected allografts into anti-CD40L-treated recipients. Intragraft expression of CTGF was readily detectable as early as day 7 posttransplantation of hTGF $\beta$-transfected allografts. Further, fibrosis and TAV were evident by day 30 in these hTGF $\beta$ transfected allografts (data not shown).

\section{TGFß transfection does not induce CTGF expression and $C R$ in syngeneic cardiac grafts}

It is well established that syngeneic grafts do not develop CR rejection to the extent that allografts do $(1,5)$, thereby supporting a critical role for the immune system in the progression of $C R$. What is less clear is what role the immune system might play in TGF $\beta$ induction of CTGF and the subsequent development of $\mathrm{CR}$. To this end, we assessed the impact of intragraft expression of active hTGF $\beta$ and CTGF induction in syngeneic grafts. As expected, transgene expression was readily detected in Ad-TGF $\beta$-transfected syngeneic grafts (Figure 3A). However, CTGF was either weakly expressed or was not detectable in these 
A

\section{hTGF $\beta$}

\section{CTGF}

Actin
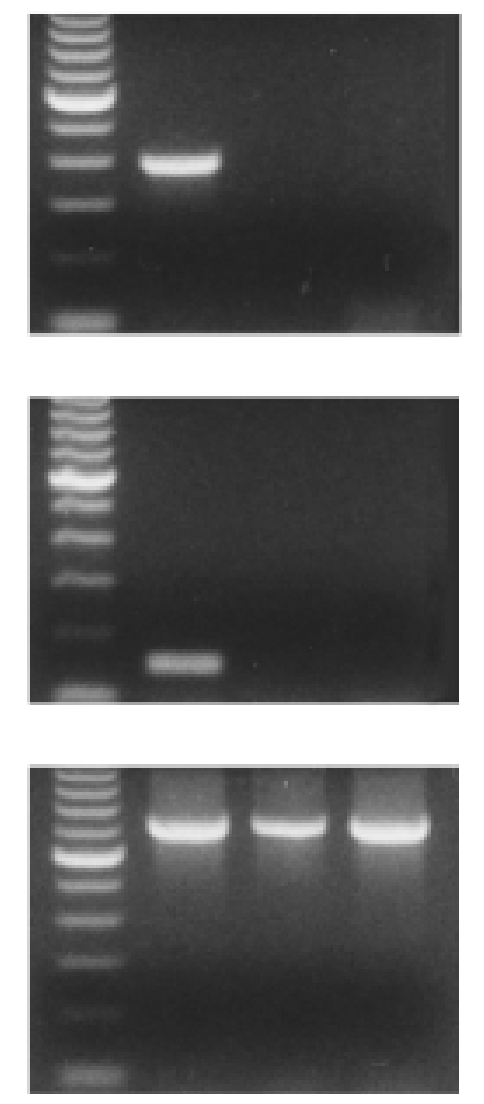

Figure 2. Forced expression of TGF $\beta$ induces CTGF and CR anti-CD40L-treated allograft recipients. BALB/C allografts were transfected with Ad-TGF $\beta$ or Ad- $\beta$ gal and transplanted into antiCD40L-treated C57BL/6 recipients. Functioning allografts were recovered between days 50 and 60 post-transplant. Panel A depicts RT-PCR for the hTGF $\beta$ transgene-induced CTGF, while Panel B depicts the histologic assessment of CR (200X). Data in Panels $A$ and $B$ are representative of $>20$ individual transplants for each group. Panel C depicts immunohistochemical localization of CTGF in TGF $\beta$-transfected allografts and the data are representative of 12 individual transplants for the Ad-TGF $\beta$ group and 6 transplants for the Ad- $\beta$ gal group.
TGF $\beta$-transfected syngeneic grafts. To validate differences in the levels of CTGF expression in TGF $\beta$-transfected syngeneic and allogeneic transplants, we performed real-time PCR for CTGF in these grafts (Figure 3B, left panel). Significantly less CTGF was expressed in TGF $\beta$-transfected syngeneic transplants relative to their allogeneic counterparts. We also assessed the level of collagen type I expression in these tissues, since CTGF is known to induce collagen production $(8,14)$ and collagen deposition is a hallmark of CR $(2,3)$. As was the case with CTGF expression, collagen expression was significantly reduced in TGF $\beta$-transfected syngeneic grafts when compared to allografts (Figure 3B, right panel). Importantly, the failure of active TGF $\beta$ expression to induce CTGF and subsequent collagen expression correlated with the absence of histologically defined $\mathrm{CR}$ in syngeneic grafts (Figure $3 \mathrm{C}$ ). It is possible that the hTGF $\beta$ transgene is expressed at lower levels in syngeneic grafts when compared to allografts, thereby resulting in less CTFG and collagen expression. The primers we use to specifically amplify hTGF $\beta$ were designed for standard RTPCR and are not suited for quantitative RT-PCR. Hence, we were unable to quantitatively compare expression levels of the hTGF $\beta$ transgene in syngeneic and allogeneic grafts. However, it should be noted that equally intense bands for hTGF $\beta$ were observed in Figure 2A for allografts and Figure $3 \mathrm{~A}$ for syngeneic grafts as determined by standard RT-PCR. Further, we have reported that similar levels of $\beta \mathrm{gal}$ are expressed in Ad- $\beta$ gal-transfected syngeneic and allogeneic grafts as visually determined by $\mathrm{X}$-gal staining (33). Hence, we believe that the differences in CTGF and collagen expression in Ad-TGF $\beta$-transfected syngeneic and allogeneic grafts are not likely due to differential expression of the hTGF $\beta$ transgene.

While TGF $\beta$ has been implicated in CR (11), the mechanism by which this pleiotropic cytokine contributes to the disease process has not been defined. This study reveals a strict correlation between TGF $\beta$-induced CTGF and the development of CR. Indeed, the expression of active TGF $\beta$ in the absence of CTGF was not sufficient to drive CR (Figure 3). This is in keeping with the observation of Mori et al. (36), who reported that both TGF $\beta$ and CTGF were required to induce chronic fibrosis when injected subcutaneously. While TGF $\beta$ is the principal inducer of CTGF $(8,14,15)$, thrombin $(37,38)$ and hypoxia $(39)$ have also been shown to induce CTGF. It is conceivable that allografts may be exposed to thrombin and hypoxia, which may lead to further CTGF production. It should be noted that TNF $\alpha(40)$, IL-4 (41), and prostaglandins and prostacyclins $(42,43)$ antagonize CTGF. Hence, CTGF may be therapeutically inhibited for the treatment of fibrotic diseases (44), including CR. This approach would spare the anti-inflammatory activities of TGF $\beta$, which are believed to be beneficial in the context of transplantation.

The observations that TGF $\beta$-transfected syngeneic grafts failed to express CTGF and develop CR (Figure 3) suggest 
B

$B$
Anti-CD40L + AdTGF $\beta 1$
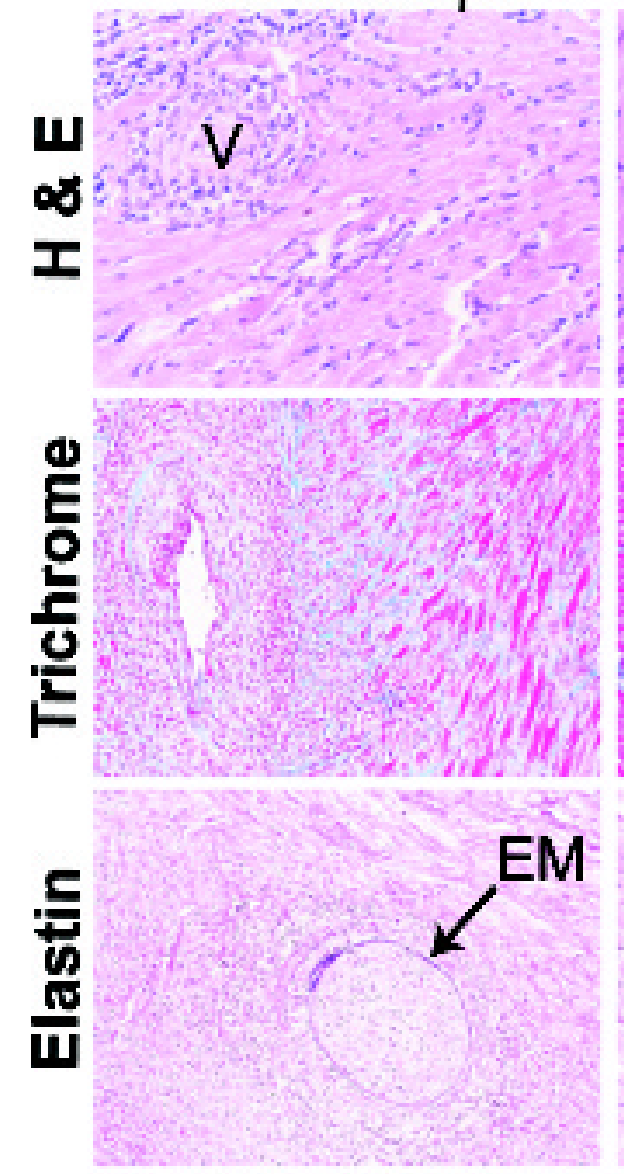

\section{Anti-CD40L + Adßgal}
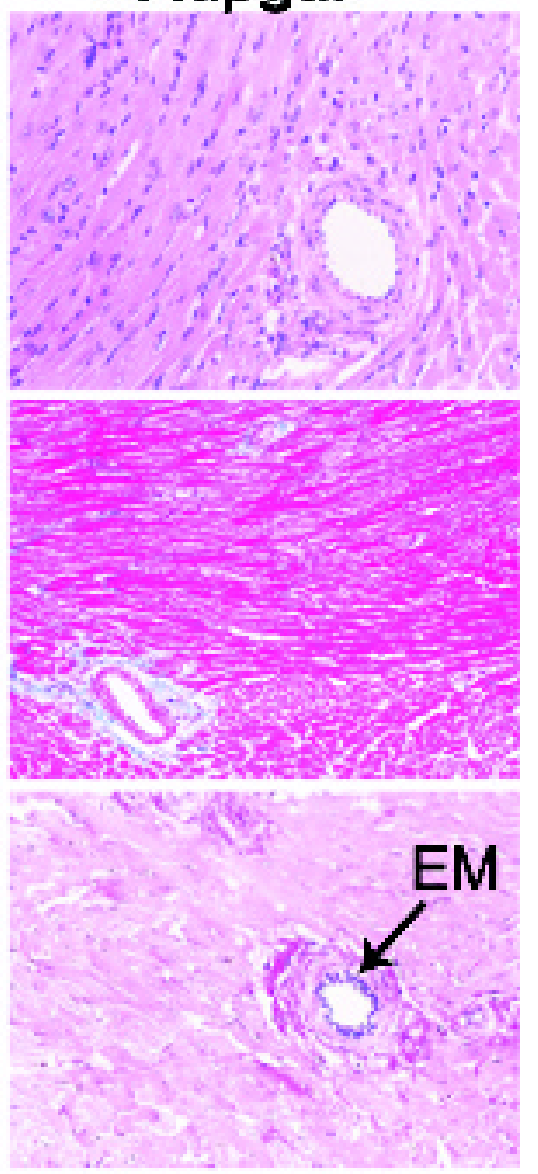

C

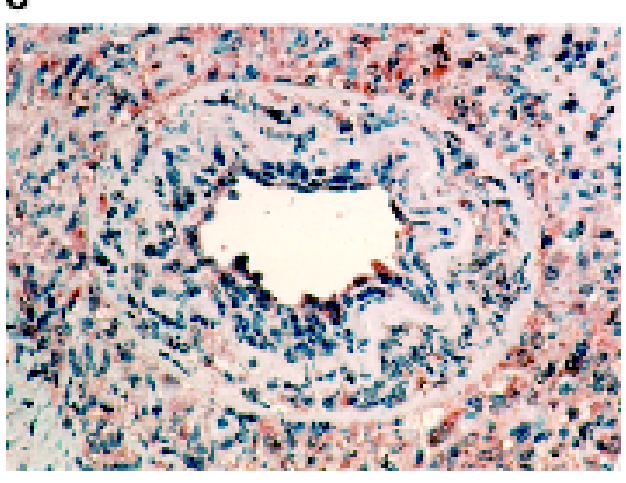

AdTGF $\beta$
Figure 2. Continued.

that a component of the immune system is necessary to drive CTGF production in this system. It should be noted that human $\gamma \delta$, but not $\alpha \beta$ T cells have been shown to produce CTGF in response to TGF $\beta$ and IL-15 (45). In addition, NK cells, which may respond to MHC disparate allo-

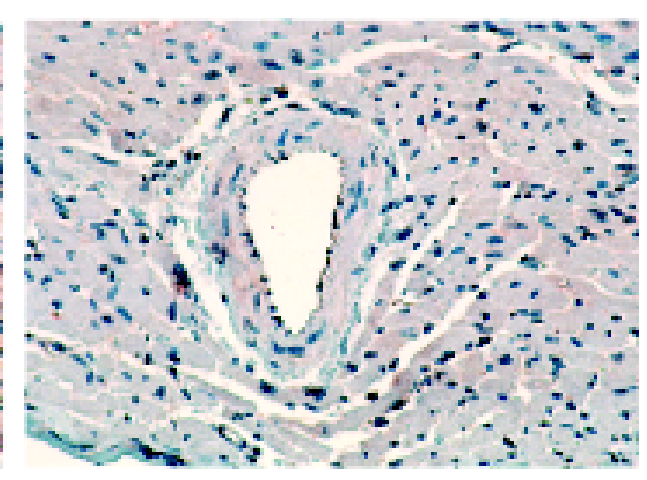

Adßgal

grafts, have recently been shown to play a role in CR (46). Further, TGF $\beta$-transfected allografts, but not syngeneic grafts, were infiltrated by mononuclear cells (Figures 2B vs. $3 \mathrm{C}$ ), and these graft-infiltrating cells expressed CTGF (Figure $2 \mathrm{C}$ ). The contribution of the immune response to 


\section{Csencsits et al.}

A
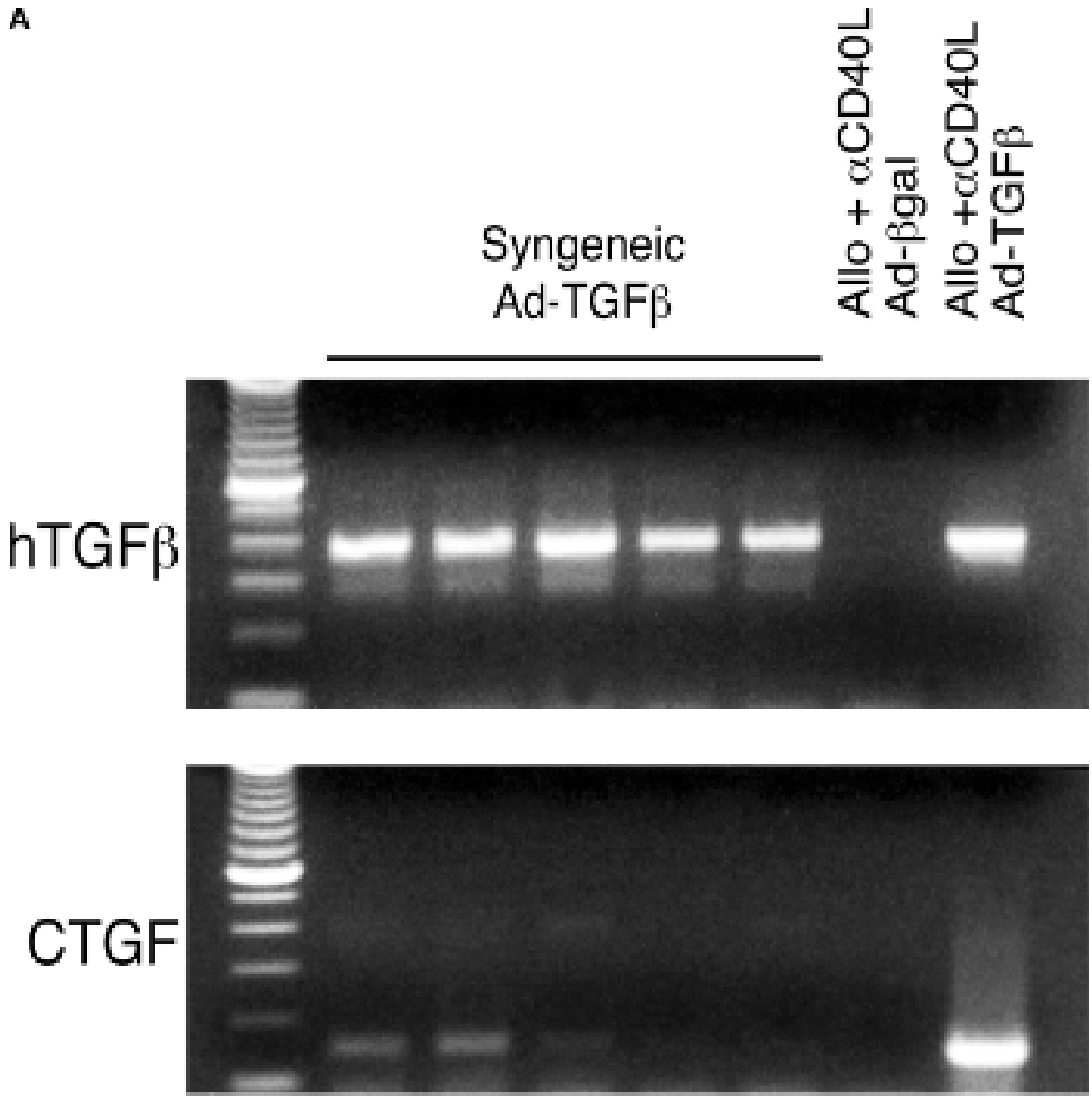

Figure 3. TGF $\beta$ transfection of syngeneic grafts does not induce CTGF or CR. C57BL/6 grafts were transfected with Ad-TGF $\beta$ and transplanted into $\mathrm{C} 57 \mathrm{BL} / 6$ recipients. Ad-TGF $\beta$-transfected BALB/C allografts transplanted into anti-CD40L-treated C57BL/6 recipients served as positive controls. Functioning grafts were recovered between days 50 and 60 post-transplant. Panel A depicts RT-PCR results for 5 TGF $\beta$-transfected syngeneic grafts. Note weak CTGF bands detected in 2 syngeneic grafts relative to the allograft control. Panel B depicts real-time RT-PCR data for CTGF (left panel) and collagen (right panel) in 5 individual transplants per group. Panel C depicts the absence of $\mathrm{CR}$ in TGF $\beta$-transfected syngeneic grafts.

CR is well established $(1,5)$. This study provides insight as to how elements of the immune response may do so.

\section{Acknowledgment}

This work was supported by an American Society of Transplantation Basic Science Fellowship (KC) and R01 Al031946 (DKB) and R01 HL070613 (DKB) from the National Institutes of Health.

\section{References}

1. Häyry $P$, Isoniemi $H$, Yilmaz $S$ et al. Chronic allograft rejection. Immunol Rev 1993; 134: 33-81.
2. Libby P, Pober JS. Chronic rejection. Immunity 2001; 14: 387397.

3. Orosz CG, Pelletier RP. Chronic remodeling pathology in grafts. Curr Opin Immunol 1997; 9(5): 676-680.

4. Weis $M$, von Scheidt W. Cardiac allograft vasculopathy: A review. Circulation 1997; 96: 2069-2077.

5. Waaga AM, Gasser M, Laskowski I, Tilney NL. Mechanisms of chronic rejection. Curr Opin Immunol 2000; 12: 517-521.

6. Tullius SG, Tilney NL. Both alloantigen-dependent and -independent factors influence chronic allograft rejection. Transplantation 1995; 59: 313-318.

7. Border WA, Ruoslahti E. Transforming growth factor-beta in disease: The dark side of tissue repair. J Clin Invest 1992; 90: 17. 

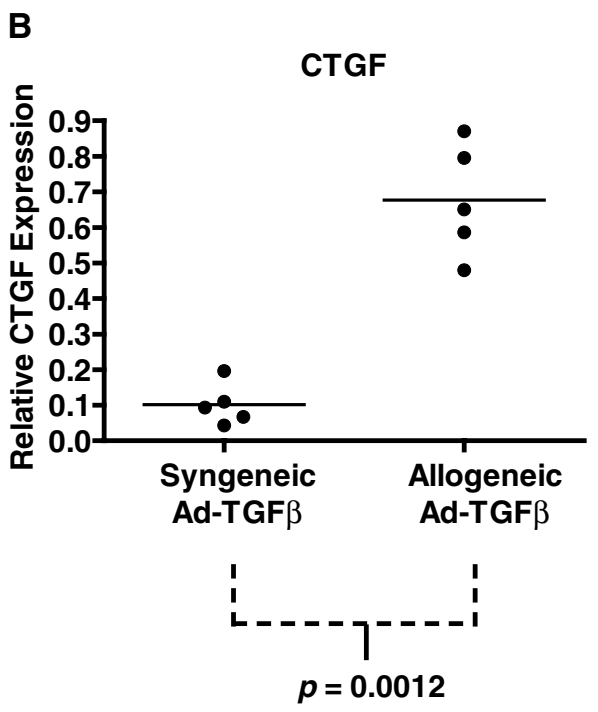
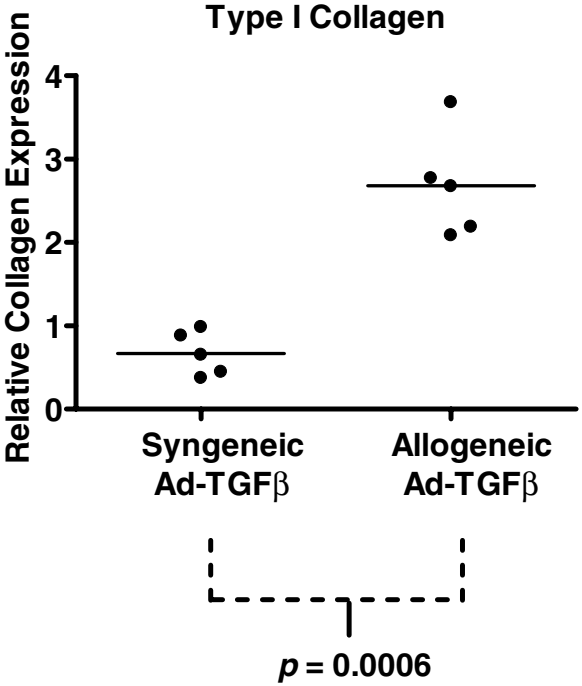
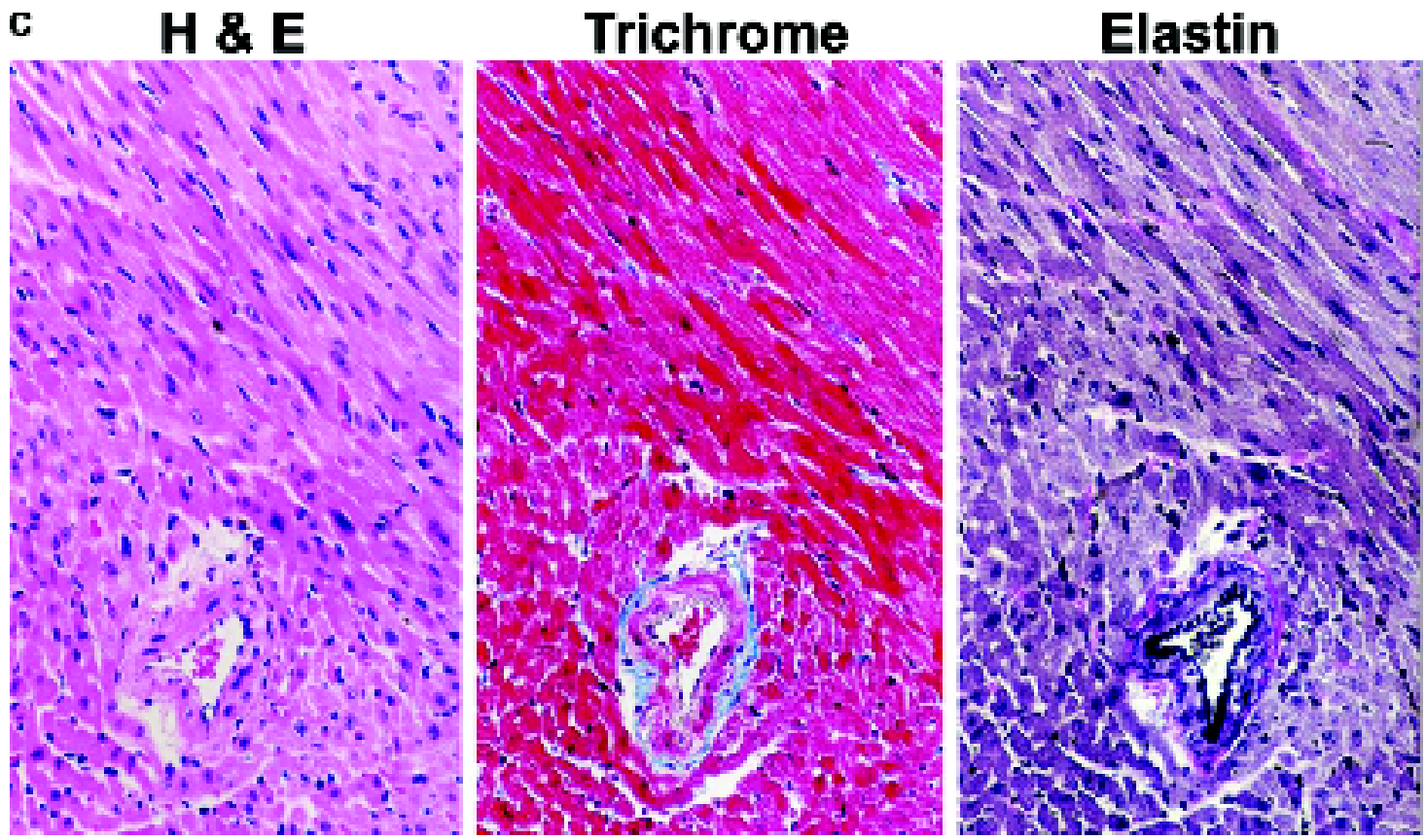

Figure 3. Continued.

8. Franklin TJ. Therapeutic approaches to organ fibrosis. Int $J$ Biochem Cell Biol 1997; 29: 79-89.

9. Wahl SM. Transforming growth factor $\beta$ : The good, the bad, and the ugly. J Exp Med 1994; 180: 1587-1590.

10. Tabibzadeh S. Homeostasis of extracellular matrix by TGF- $\beta$ and lefty. Front Biosci 2002; 7: d1231-1246.

11. Jain S, Furness PN, Nicholson ML. The role of transforming growth factor beta in chronic renal allograft nephropathy. Transplantation 2000; 69: 1759-1766.

12. Letterio JJ, Roberts AB. Regulation of immune responses by TGFbeta. Annu Rev Immunol 1998; 16: 137-161.
13. Brattain MG, Markowitz SD, Willson JK. The type II transforming growth factor-beta receptor as a tumor-suppressor gene. Curr Opin Oncol 1996; 8: 49-53.

14. Gupta S, Clarkson MR, Duggan J, Brady HR. Connective tissue growth factor: Potential role in glomerulosclerosis and tubulointerstitial fibrosis. Kidney Int 2000; 58: 1389-1399.

15. Leask A, Abraham DJ. The role of connective tissue growth factor, a multifunctional matricellular protein, in fibroblast biology. Biochem Cell Biol 2003; 81: 355-363.

16. Grotendorst GR, Okochi H, Hayashi N. A novel transforming growth factor beta response element controls the expression 
of the connective tissue growth factor gene. Cell Growth Differ 1996; 7: 469-480.

17. Frazier K, Williams S, Kothapalli D, Klapper H, Grotendorst GR. Stimulation of fibroblast cell growth, matrix production, and granulation tissue formation by connective tissue growth factor. J Invest Dermatol 1996; 107: 404-411.

18. Igarashi $A$, Nashiro K, Kikuchi $K$ et al. Connective tissue growth factor gene expression in tissue sections from localized scleroderma, keloid, and other fibrotic skin disorders. J Invest Dermatol 1996; 106: 729-733.

19. Dammeier J, Brauchle M, Falk W, Grotendorst GR, Werner S. Connective tissue growth factor: A novel regulator of mucosal repair and fibrosis in inflammatory bowel disease? Int J Biochem Cell Biol 1998; 30: 909-922.

20. di Mola FF, Friess H, Martignoni ME et al. Connective tissue growth factor is a regulator for fibrosis in human chronic pancreatitis. Ann Surg 1999; 230: 63-71.

21. Shi-wen $X$, Pennington $D$, Holmes $A$ et al. Autocrine overexpression of CTGF maintains fibrosis: RDA analysis of fibrosis genes in systemic sclerosis. Exp Cell Res 2000; 259: 213-224.

22. Paradis V, Dargere D, Vidaud $M$ et al. Expression of connective tissue growth factor in experimental rat and human liver fibrosis. Hepatology 1999; 30: 968-976.

23. Chen MM, Lam A, Abraham JA, Schreiner GF, Joly AH. CTGF expression is induced by TGF- beta in cardiac fibroblasts and cardiac myocytes: A potential role in heart fibrosis. J Mol Cell Cardiol 2000; 32: 1805-1819.

24. Uzel MI, Kantarci A, Hong HH et al. Connective tissue growth factor in drug-induced gingival overgrowth. J Periodontol 2001; 72: 921-931.

25. Wang S, Denichilo M, Brubaker C, Hirschberg R. Connective tissue growth factor in tubulointerstitial injury of diabetic nephropathy. Kidney Int 2001; 60: 96-105.

26. Leask A, Holmes A, Abraham DJ. Connective tissue growth factor: A new and important player in the pathogenesis of fibrosis. Curr Rheumatol Rep 2002; 4: 136-142.

27. Razzaque MS, Foster CS, Ahmed AR. Role of connective tissue growth factor in the pathogenesis of conjunctival scarring in ocular cicatricial pemphigoid. Invest Ophthalmol Vis Sci 2003; 44: 19982003.

28. Corry RJ, Winn HJ, Russell PS. Primarily vascularized allografts of hearts in mice. The role of $\mathrm{H}-2 \mathrm{D}, \mathrm{H}-2 \mathrm{~K}$, and non- $\mathrm{H}-2$ antigens in rejection. Transplantation 1973; 16: 343-350.

29. Piccotti JR, Li K, Chan SY, Eichwald EJ, Bishop DK. Cytokine regulation of chronic cardiac allograft rejection: Evidence against a role for Th1 in the disease process. Transplantation 1999; 67: 15481555.

30. Bishop DK, Shelby J, Eichwald EJ. Mobilization of T lymphocytes following cardiac transplantation: Evidence that CD4-positive cells are required for cytotoxic $T$ lymphocyte activation, inflammatory endothelial development, graft infiltration, and acute allograft rejection. Transplantation 1992; 53: 849-857.

31. Bishop DK, Chan Wood S, Eichwald EJ, Orosz CG. Immunobiology of allograft rejection in the absence of IFN-gamma: CD8+ effector cells develop independently of CD4+ cells and CD40-CD40 ligand interactions. J Immunol 2001; 166: 3248-3255.
32. Nathan MJ, Yin D, Eichwald EJ, Bishop DK. The immunobiology of inductive anti-CD40L therapy in transplantation: Allograft acceptance is not dependent upon the deletion of graft-reactive T cells. Am J Transplant 2002; 2: 323-332.

33. Chan SY, Li K, Piccotti JR et al. Tissue-specific consequences of the anti-adenoviral immune response: Implications for cardiac transplants. Nat Med 1999; 5: 1143-1149.

34. Chan SY, Goodman RE, Szmuszkovicz JR, Roessler B, Eichwald EJ, Bishop DK. DNA-liposome versus adenoviral mediated gene transfer of transforming growth factor beta 1 in vascularized cardiac allografts: Differential sensitivity of CD4+ and CD8+ T cells to transforming growth factor beta1. Transplantation 2000; 70: 1292-1301.

35. Steffen CL, Ball-Mirth DK, Harding PA, Bhattacharyya N, Pillai $\mathrm{S}$, Brigstock DR. Characterization of cell-associated and soluble forms of connective tissue growth factor (CTGF) produced by fibroblast cells in vitro. Growth Factors 1998; 15: 199-213.

36. Mori T, Kawara S, Shinozaki M et al. Role and interaction of connective tissue growth factor with transforming growth factor-beta in persistent fibrosis: A mouse fibrosis model. J Cell Physiol 1999; 181: 153-159.

37. Chambers RC, Leoni P, Blanc-Brude OP, Wembridge DE, Laurent GJ. Thrombin is a potent inducer of connective tissue growth factor production via proteolytic activation of protease-activated receptor-1. J Biol Chem 2000; 275: 35584-35591.

38. Howell DC, Goldsack NR, Marshall RP et al. Direct thrombin inhibition reduces lung collagen, accumulation, and connective tissue growth factor mRNA levels in bleomycin-induced pulmonary fibrosis. Am J Pathol 2001; 159: 1383-1395.

39. Kondo S, Kubota S, Shimo T et al. Connective tissue growth factor increased by hypoxia may initiate angiogenesis in collaboration with matrix metalloproteinases. Carcinogenesis 2002; 23: 769776.

40. Abraham DJ, Shiwen X, Black CM, Sa S, Xu Y, Leask A. Tumor necrosis factor alpha suppresses the induction of connective tissue growth factor by transforming growth factor- $\beta$ in normal and scleroderma fibroblasts. J Biol Chem 2000; 275: 15220-15225.

41. Rishikof DC, Ricupero DA, Kuang PP, Liu H, Goldstein RH. Interleukin-4 regulates connective tissue growth factor expression in human lung fibroblasts. J Cell Biochem 2002; 85: 496-504.

42. Ricupero DA, Rishikof DC, Kuang PP, Poliks CF, Goldstein RH. Regulation of connective tissue growth factor expression by prostaglandin $E_{2}$. Am J Physiol 1999; 277: L1165-1171.

43. Stratton R, Shiwen X, Martini G et al. Iloprost suppresses connective tissue growth factor production in fibroblasts and in the skin of scleroderma patients. J Clin Invest 2001; 108: 241-250.

44. Blom IE, Goldschmeding R, Leask A. Gene regulation of connective tissue growth factor: New targets for antifibrotic therapy? Matrix Biol 2002; 21: 473-482.

45. Workalemahu G, Foerster M, Kroegel C, Braun RK. Human $\gamma / \delta$ $T$ lymphocytes express and synthesize connective tissue growth factor: Effect of IL-15 and TGF- $\beta 1$ and comparison with $\alpha / \beta-T$ lymphocytes. J Immunol 2003; 170: 153-157.

46. Uehara S, Chase CM, Kitchens WH et al. NK cells can trigger allograft vasculopathy: The role of hybrid resistance in solid organ allografts. J Immunol 2005; 175: 3424-3430. 